\title{
SINERGIA
}

REVISTA DO INSTITUTO DE CIÊNCIAS ECONÔMICAS, ADMINISTRATIVAS E CONTÁBEIS (ICEAC)

\section{CONHECIMENTO CONTÁBIL E FISCAL E AS FONTES DE ASSESSORAMENTO CONTÁBIL: UMA COMPARAÇÃO ENTRE PRODUTORES RURAIS COOPERADOS E NÃO COOPERADOS}

\author{
CRISTIANE KRÜGER \\ LIZANA ILHA DA SILVA* \\ LARISSA MARTINS TONETTO***
}

\begin{abstract}
RESUMO
Este estudo objetivou analisar produtores rurais cooperados e não cooperados quanto ao conhecimento contábil e fiscal, preparação e apoio para a nota fiscal eletrônica, e a utilização dos serviços do profissional contábil ou de outras fontes de assessoramento. Para atingir esse objetivo, adotou-se uma metodologia quantitativa, descritiva e de levantamento. A coleta de dados contemplou um questionário aplicado a 110 produtores rurais de Santa Maria, sendo 55 associados de cooperativas rurais e 55 não cooperados. Os dados foram analisados por meio de estatística descritiva, Alfa de Cronbach e Teste "U" de Mann-Whitney para amostras independentes. Os resultados apontaram que os produtores rurais que são cooperados de cooperativas agropecuárias apresentam maior conhecimento contábil e fiscal, utilizam mais o profissional da área contábil e outras fontes de assessoramento e estão mais preparados para a NFE frente aos produtores rurais que não são cooperados.
\end{abstract}

Palavras-chave: Conhecimento e assessoramento contábil. Cooperativismo. Agronegócio.

\section{ABSTRACT}

This study objective to analyze cooperative and non-cooperative rural producers in terms of accounting and tax knowledge, preparation and support for the electronic invoice, and the use of the services of the accounting professional or other sources of advice. To achieve this objective, a quantitative, descriptive and survey methodology was adopted. The data collection included a questionnaire applied to 110 rural producers in Santa Maria, being 55 members of rural cooperatives and 55 non-cooperative. Data were analyzed using descriptive statistics, Cronbach's alpha and MannWhitney "U" test for independent samples. The results showed that rural producers who are cooperative members of agricultural cooperatives have greater accounting and tax knowledge, use more professionals in the accounting area and other sources of advice and are better prepared for the electronic invoice compared to rural producers who are not cooperative.

Keywords: Accounting knowledge and advice. Cooperatives. Agribusiness.

Recebido em: 08-01-2021 Aceito em: 27-04-2021

\section{INTRODUÇÃO}

O cooperativismo é considerado um movimento social que leva indivíduos com necessidades comuns a estabelecerem entre si uma relação de interdependência, orientada por uma filosofia de vida (KAMUTALI; HENRIQUES; LUCAS, 2020). Os autores ressaltam que as necessidades comuns são satisfeitas com base na solidariedade, na equidade e no respeito do homem pelo homem, tendo como foco a entreajuda e o encontro de soluções de problemas de uma forma coordenada e coletiva. Assim, o surgimento do cooperativismo é visto como uma forma de atender a aspectos sociais e econômicos no contexto da coletividade, sendo um meio pelo qual os cooperados podem, ao mesmo tempo, gerir as entidades e obter diversos benefícios (ICA, 2020).

Dentro do cenário do cooperativismo, destacam-se os pequenos e médios produtores rurais que, cada vez mais, têm contado com o apoio do ramo do cooperativismo rural ou do cooperativismo do agronegócio para a ampliação de mercado comercial e para a elevação de renda (FUZINATTO et al., 2019). Bialoskorski Neto e Pinto (2012) reforçam que as cooperativas do agronegócio possuem expressiva quantidade de

\footnotetext{
" Doutora e Mestra em Administração pela Universidade Federal de Santa Maria. Especialista em Gestão Pública e em Contabilidade, Perícia e Auditoria. Professora Adjunta do Departamento de Ciências Contábeis da Universidade Federal de Santa Maria. E-mail: cristiane.kruger@ufsm.br

" Mestranda em Contabilidade pela Universidade Federa de Santa Catarina e professora substituta do Colégio Politécnico da UFSM, da Universidade Federal de Santa Maria. Graduação em Ciências Contábeis pela Universidade Federal de Santa Maria.

*** Graduanda em Ciências Contábeis pela Universidade Federal de Santa Maria (UFSM).
} 
associados, os quais são considerados, geralmente, pequenos produtores rurais.

Nesse contexto, a relevância do cooperativismo consiste no fato de se tratar de uma organização que é capaz de mudar hábitos e comportamentos, agir com outra racionalidade e condicionar novas posturas entre os seus participantes (GIANEZINI et al., 2009). Segundo Fuzinatto et al. (2019), o sistema cooperativista faz com que os cidadãos evoluam social, econômica e culturalmente, e o associativismo também promove um acesso facilitado ao conjunto de políticas públicas destinadas ao desenvolvimento do agronegócio nas pequenas e médias propriedades. De forma mais específica, observa-se, nas cooperativas do agronegócio, uma relação mais próxima entre a cooperativa e o associado, por meio da prestação de serviços, de assistência técnica, além da comercialização e de agregação de valor à produção (BIALOSKORSKI NETO; PINTO, 2012).

Entende-se que a cooperação espontânea dá continuidade ao movimento político de luta pela melhoria das condições de vida no campo, amplia e dinamiza as formas e as redes de convivência social que favorecem a resistência e a permanência dos produtores rurais no campo (SCOPINHO, 2007). Destaca-se, ainda, que é de fundamental importância a promoção do associativismo para pequenos e médios produtores rurais, incentivando formas de participação coletiva, principalmente, no caso de produtores mais carentes, com menor grau de escolaridade que resistem a essa prática por falta de informação ou por dificuldade de entendimento e de opções (KAMUTALI; HENRIQUES; LUCAS, 2020).

Nesse sentido, os proprietários das cooperativas são seus membros, assim, os cooperados assumem duplo papel (usuário/proprietário) (MACIEL et al., 2018). Além disso, as cooperativas criam valor quando conseguem atender com êxito as demandas de seus cooperados, e agregam informações em relação às necessidades dos membros em resultados como produtos e/ou serviços (REYNOLDS, 2013). Segundo a autora, para que as cooperativas sejam bem-sucedidas, é necessário que elas encontrem o equilíbrio entre as necessidades de seus membros e a sustentabilidade econômica de longo prazo na cooperativa. Dessa maneira, cada cooperativa formula suas estratégias a partir dos interesses de seus associados, fato esse que faz com que as cooperativas tenham características particulares, assim como as cooperativas do agronegócio que buscam suprir as necessidades dos seus, resultando em decisões estratégicas que as diferenciam uma das outras (BIALOSKORSKI NETO; PINTO, 2012).

Além da cooperativa, para auxiliar nas tomadas de decisões dos produtores rurais, insere-se o profissional da contabilidade. Essa fonte de apoio origina informações que afetam a gestão do setor do agronegócio e pode contribuir para a ampliação das atividades e melhoria dos processos que gerem incrementos nos resultados financeiros, pois a competitividade econômica faz parte do agronegócio (AMBRÓS et al., 2019). É preciso enxergar o produtor rural como gestor de uma atividade econômica e de um patrimônio, sendo possível a utilização de ferramentas de gestão, ajustadas às necessidades e particularidades existentes em cada propriedade, que permitam planejar e controlar a gestão e a continuidade dos negócios desenvolvidos no meio rural (KRUGER; CECCHIN; MORES, 2020).

Com base nisso, Crepaldi (2019, p. 39) afirma que se faz necessário manter profissionais de contabilidade qualificados "para operarem nas atividades rurais, tanto na própria produção como na área administrativa, visando buscar um controle econômico-financeiro mais rigoroso". Em contrapartida, na atividade rural de pequenas e médias propriedades, na qual não há constituição da pessoa jurídica, os proprietários possuem a liberdade de optar pelo assessoramento de profissionais da área contábil ou de buscar outras formas de apoio à gestão, como os sindicatos e as cooperativas aos quais estão vinculados (AMBRÓs et al., 2019).

Diante do exposto, as cooperativas e os profissionais de contabilidade podem ser considerados, direta ou indiretamente, fontes de assessoramento aos produtores rurais, e, considerando que a adesão junto às cooperativas acontece de forma voluntária, assim como a utilização dos serviços do profissional contábil não é obrigatória para os mesmos, questiona-se: qual a diferença entre produtores rurais cooperados e não cooperados quanto ao conhecimento contábil e fiscal, preparação e apoio para a Nota Fiscal Eletrônica (NFE), e a utilização dos serviços do profissional contábil ou de outras fontes de assessoramento?

Para tanto, este estudo buscou analisar produtores rurais cooperados e não cooperados quanto ao conhecimento contábil e fiscal, preparação e apoio para a NFE, e a utilização dos serviços do profissional contábil ou de outras fontes de assessoramento. Como forma de alcançar o objetivo apresentado, foram estabelecidos os seguintes objetivos específicos: I. apresentar o perfil dos produtores rurais pesquisados; II. verificar os conhecimentos contábil e fiscal, e a preparação e apoio para a NFE dos produtores rurais investigados; III. identificar a utilização dos serviços do profissional contábil e de outras fontes de assessoramento pelos produtores rurais; IV. comparar conhecimentos contábil e fiscal, preparação e apoio para a NFE, e as fontes de assessoramento dos produtores rurais cooperados e não cooperados.

O presente estudo é motivado por investigar a atuação do profissional contábil e de outras fontes de assessoramento, no meio rural, uma vez que os agricultores, na sua maioria, não se utilizam de assessoria contábil (AMBRÓS et al., 2019). Complementarmente, entende-se que as informações originadas pelos profissionais contábeis afetam a gestão do setor agrícola e das cooperativas como um todo e podem contribuir 
para ampliação das atividades e incrementos nos resultados financeiros, o que justifica a realização deste estudo (AMBRÓS et al., 2019).

Outra razão para a realização desta pesquisa refere-se à contribuição para com a classe contábil quanto ao levantamento desta prática junto aos produtores rurais, bem como a contribuição para as cooperativas do agronegócio, uma vez que pode apresentar lacunas que podem servir como oportunidade para que as cooperativas aumentem a abrangência do seu suporte técnico aos cooperados. Para as cooperativas, a contabilidade se torna um diferencial que contribui para o crescimento e estruturação de suas unidades, além de servir como apoio aos seus cooperados (PEREIRA, 2020), reforçando, ainda mais, a importância da contabilidade como suporte para as cooperativas e, consequentemente, para os produtores rurais cooperados.

No intuito de responder ao problema levantado, este artigo é dividido em seções. Inicialmente, na introdução, apresentaram-se delimitação do tema, problema de pesquisa, objetivos, geral e específicos, e a justificativa. Com base nisso, a próxima seção contempla o referencial teórico que aborda conteúdos fundamentais para a compreensão da temática pesquisada, como o cooperativismo e a contabilidade no agronegócio. Posteriormente, apresenta-se a metodologia do estudo, que descreve o enquadramento científico, bem como detalha a coleta e a análise dos dados. Em seguida, a quarta seção refere-se à análise e à discussão dos resultados. Por fim, a última seção corresponde à conclusão que resgata os objetivos estabelecidos e apresenta os resultados auferidos e, ainda, descreve contribuições, limitações e sugestões para estudos futuros.

\section{RESGATE HISTÓRICO DO COOPERATIVISMO}

O cooperativismo nasceu na Inglaterra, no fim do século XVIII, meados do século XIX, período posterior à revolução industrial (MAFFIOLETTI, 2015). Esse período foi marcado pelo descontentamento dos trabalhadores em função da baixa nos salários e da alta taxa de desemprego. Isso ocasionou a união da classe em busca de melhores condições e o surgimento de precursores como Robert Owen (1771-1858), Charles Fourier (1772-1837), Benjamin Buchez (1796-1865), Louis Blanc (1812-1882), entre outros, que acreditavam em um modelo alterno ao individualismo, o que passou a ser denominado de cooperativismo (PINHO, 1966).

Desse sentimento de indignação, conforme consta no Sistema OCB - Núcleo de Informações e Mercado (2019), originou-se a cooperativa, que é a união de pessoas, de natureza jurídica própria, que desempenham a mesma função e têm como objetivo a ascensão e o espaço no mercado. A primeira cooperativa é datada de 1844, na Inglaterra, na qual 28 trabalhadores uniram forças e fundaram a "Sociedade dos Probos de Rochdale" (MAFFIOLETTI, 2015). Segundo o autor, num primeiro momento, esses cooperados comercializavam apenas alimentos, com o objetivo de obter produtos com valores mais acessíveis, posteriormente as atividades foram ampliadas.

Anos depois, na França, Benjamin Buchez e Louis Blanc, inspirados pelo movimento inglês que começava a se difundir entre as regiões, deram início à cooperativa de produção e à associação de trabalhadores na região (POLONIO, 2004). Em seguida, em 1849, na Alemanha, já estava consolidada a primeira cooperativa de crédito e consumo da região; fundada por Herman Schulze, a cooperativa tinha como público-alvo pequenos produtores e artesãos (POLONIO, 2004).

No Brasil, somente em 1889, foi constituída a primeira cooperativa na cidade de Ouro Preto, em Minas Gerais (JACQUES; GONÇALVES, 2016). Foi uma iniciativa pioneira no País. Com a Cooperativa Econômica dos Funcionários Públicos de Ouro Preto, os associados tinham como foco o consumo de produtos agrícolas. Assim, abriu-se portas para a expansão do modelo econômico em outras regiões, como o Rio Grande do Sul, em 1902, com o surgimento da primeira cooperativa de crédito do país, a Sicredi, que segue em funcionamento no mercado (JACQUES; GONÇALVES, 2016).

A partir dessa expansão e do constante crescimento, o Estado regulamentou o Decreto n. 1.637 (BRASIL, 1907), no qual a cooperativa era descrita como similar às sociedades anônimas, o que vinha ao desencontro do que já pregava a doutrina cooperativista, na qual as cooperativas são declaradas de natureza jurídica própria (POLONIO, 2004). No decorrer dos anos, foram criados e lançados outros decretos, como o Decreto de Lei n. 59 (BRASIL, 1966), no qual o Estado detinha intervenção nas cooperativas.

Foi somente com o início da ditadura militar e com a queda considerável no setor cooperativista que os cooperados uniram forças e, juntamente com grupos internacionais, buscaram defender o movimento cooperativista na América Latina, o que resultou na criação da Organização das Cooperativas Brasileiras (OCB) e, posteriormente, o anteprojeto da Lei 5.764 (BRASIL, 1971), atual Lei das Sociedades Cooperativas (MAFFIOLETTI, 2015). Em seguida, com a Constituição Federal (BRASIL, 1988), as cooperativas deixaram de ser sociedades civis e passaram a ser sociedades simples, deixando de ser classificadas como sociedades empresarias, passando a possuir a liberdade de associação sem intervenção estatal, entre outras mudanças decorridas em função da Lei 10.406 (BRASIL, 2002). 
Além da evolução legislativa, com o passar dos anos, as cooperativas foram se desenvolvendo, o Sistema OCB (2019) aponta que, em 2018, o Brasil já detinha um total de 6.828 cooperativas em todo território nacional, lideradas pelos Estados de Minas Gerais e São Paulo. O total de cooperados, no Brasil, chegou a 14,6 milhões, entre homens e mulheres, em sua maioria, com idades entre 41 e 45 anos (OCB, 2019). Essa evolução crescente do cooperativismo vem gerando, cada vez mais, empregos e renda; de 2014 a 2018, foram mais de 64 mil vagas originadas das mais diversas cooperativas, em contraponto, no mesmo período, o setor privado teve queda de $5 \%$, o que representa 2,3 milhões de empregos a menos (OCB, 2019), o que destaca o cooperativismo.

Diante disso, o cooperativismo tem um caráter social e segue uma corrente doutrinaria voltada para uma rede de princípios e valores fundamentais para o desenvolvimento econômico e social da entidade, que tem por objetivo a igualdade no meio (MIRANDA, 2017). Nesse sentido, o princípio da adesão livre e voluntária traz a ideia de que todos que estão desimpedidos, jurídica e tecnicamente, devem ter a oportunidade de tornarem-se um cooperado independente de cor, gênero, raça e crença (BRASIL, 1971). A gestão democrática pelos associados, outro princípio, rege que todos têm o mesmo poder de voto e de tomada de decisão (MIRANDA, 2017).

A participação econômica dos cooperados de modo democrático, bem como o capital controlado de forma democrática e todas as decisões são tomadas de maneira que o capital seja destinado para o desenvolvimento da cooperativa, de bonificações aos membros, ou, até mesmo, para investimento a outras operações que correspondem a outros princípios cooperativistas (PIES; BAGGIO; ROMEIRO, 2016). Cabe destacar, na sequência, o princípio da autonomia e independência, que reforça esse poder democrático dos cooperados quando em contato com outras sociedades, na qual todas as pautas devem ser votadas, assim, podendo ser discutido entre os membros e tomada a decisão democraticamente (SCHNEIDER, 1991).

Ademais, o cooperativismo apresenta um princípio voltado para a educação, formação e informação, assim, os cooperados contam com treinamentos no qual podem acompanhar as mudanças do meio e auxiliar de forma mais efetiva na produção (MEINEN; PORT, 2014). De acordo com os autores, o caráter social da cooperativa consta junto aos princípios de intercooperação e interesse pela comunidade, por meio da qual as cooperativas devem servir de forma eficaz aos seus membros, proporcionando mais força ao movimento cooperativo e promovendo o desenvolvimento das suas comunidades através de políticas aprovadas pelos membros.

No Brasil, existem várias áreas/ramos de atuação das cooperativas, as cooperativas agropecuárias correspondem a um dos mais tradicionais ramos do cooperativismo, exercendo relevante papel para a economia nacional (BAGENETA; RODRÍGUEZ, 2020). Diante disso, tal temática é apresentada a seguir.

\subsection{Cooperativismo e a Contabilidade no Agronegócio}

Presente desde 1847 no Brasil, as cooperativas agropecuárias ou rurais contam com mais de 1.600 instalações no território nacional (OCB, 2019). O ramo agropecuário abrange o vínculo com diversas atividades relacionadas ao meio rural, como a pesca, a criação de animais, o extrativismo e o plantio. No Rio Grande do Sul, a ênfase está nos grãos e nos laticínios que lideram o ranking de cooperativas com mais de 45 unidades distribuídas na região gaúcha, seguidos de insumos e varejo (SESCOOP RS/2019).

O cooperativismo, no setor do agronegócio, vem mostrando, a cada ano, crescimento constante, gerando renda e emprego a milhares de pessoas, no Rio Grande do Sul, por exemplo, são mais de 36 mil empregados diretos que contribuem para que o faturamento de pelo menos $35 \%$ das cooperativas supere a casa dos 9 milhões de reais (SESCOOP RS/2019). Adicionalmente a esses dados, a cooperativa, muitas vezes, é responsável pelo processamento, comercialização de compra e venda, entre outras atividades que garantem o giro econômico mais vantajoso na produção dos cooperados, além de prestar serviços de assistência, garantindo aperfeiçoamento das atividades desenvolvidas (FREITAG; KLESENER; PLEIN, 2019).

Assim, os agricultores unem-se em cooperativas agropecuárias para enfrentarem os mercados competitivos e discutirem, comercialmente, preços e novas oportunidades (ENGEL; ALMEIDA; DEPONTI, 2017). A partir da relevância das cooperativas agropecuárias para o País e para o Estado gaúcho, insere-se a contabilidade, ciência que, para Crepaldi (2019), é uma ferramenta de apoio, planejamento e controle para a tomada de decisões relacionadas à gestão das atividades do meio rural.

A presença da contabilidade, no meio cooperativo, é indispensável, por isso que o SESCOOP RS buscou uniformizar e combinar as informações contábil-financeiras entre as cooperativas (SESCOOP RS/2014). Salienta-se que as cooperativas contribuem para o recolhimento tributário de impostos como CSLL, IRPJ, PIS, COFINS, entre outros designados pela Receita Federal, o que, em 2018, já gerava um capital de $R \$ 5,13$ bilhões, e mais de $R \$ 9,6$ bilhões de tributos e despesa com pessoal (OCB, 2019). Além do interesse governamental da contabilidade no que diz respeito à arrecadação de tributos pelas cooperativas, também existe a arrecadação realizada pelo produtor rural, geralmente, sob a forma de pessoa física que contribui 
com impostos, como o Imposto Territorial Rural (ITR) e o Imposto de Renda Pessoa Física (IRPF) (CREPALDI, 2019).

Diante disso, gerenciar as organizações que compõem o agronegócio, independentemente de sua classificação como pequena, média ou grande propriedade, é uma tarefa desafiadora, pois as decisões a serem tomadas estão envoltas a um ambiente de incertezas e riscos, tanto na produção quanto no mercado (BOEHLJE; ROUCAN-KANE; BRÖRING, 2011). Outra dificuldade reside na gestão das propriedades que é, muitas vezes, focalizada na produção e na operacionalização de atividades específicas desenvolvidas frente ao atendimento de demandas legais e contábil-financeiras (BATALHA; QUEIROZ, 2003).

Nesse sentido, é preciso entender que a propriedade rural assume o papel de empresa rural, independe do porte e do registro na junta comercial (MARION, 2017). Para o autor é na empresa rural que é explorada a capacidade produtiva da terra por meio do plantio, transformação e criação de animais. Nesse contexto, a contabilidade pode ser estudada de modo geral ou voltada para determinada área, como é o caso da contabilidade rural (CREPALDI, 2019). Essa especialidade é aplicada a empresas rurais e tem como objetivo aprofundar o conhecimento em características próprias, moldando-se a fatores que influenciam o desenvolvimento econômico das propriedades, como o ano agrícola e o exercício social, produtos com colheita em diferentes períodos, atividade rural e código civil, entre outros (CREPALDI, 2019).

Almeida (2013) destaca que o empresário rural necessita de conhecimento e habilidades para o gerenciamento e tomada de decisões, abstraindo de técnicas de produção, visão de mercado e controle de custos. Diante desta necessidade, destaca-se o importante papel do profissional de contabilidade, uma vez que é ele que fornece informações úteis à tomada de decisão, auxiliando na adoção de estratégias que possibilitam melhorar os resultados (produtividade e lucro) (PICCININ; ROSSATO, 2018). Almeida (2013) reforça a importância do profissional de contabilidade por entender que o seu papel é de extrema valia para dar suporte a todos esses assuntos, podendo proporcionar à propriedade rural um melhor gerenciamento das informações externas e internas, atingindo seu objetivo: a maximização dos lucros.

Com base no que foi apresentado, entende-se que é, nesse contexto, que se insere a cooperativa e a contabilidade como relevantes assessores para a gestão das propriedades rurais. Diante disso, encerra-se o presente referencial bibliográfico. A seguir, detalha-se a metodologia adotada nesta pesquisa.

\section{PROCEDIMENTOS METODOLÓGICOS}

O enquadramento científico metodológico deste estudo, diante do objetivo estabelecido, é, quanto à natureza, uma pesquisa aplicada, quanto à abordagem do problema, é quantitativa, quanto aos objetivos, é descritiva, e compreende como técnica de pesquisa o levantamento. A pesquisa é aplicada de modo que objetiva gerar conhecimento para a aplicação prática, visando à solução de problemas específicos (PRODANOV; FREITAS, 2013), o que vai ao encontro do objetivo desta pesquisa, que procura comparar, na prática, produtores rurais cooperados e não cooperados.

Em relação à abordagem do problema, é quantitativa, para Sampieri, Collado e Lucio (2013). Utiliza a coleta de dados para testar hipóteses, baseando-se na medição numérica e na análise estatística para estabelecer padrões em consonância com esta pesquisa, na qual se utilizam dados numéricos e análise estatística para responder ao problema de pesquisa levantado. No que tange aos objetivos, é descritiva, pois esse tipo de estudo pretende descrever os fatos e os fenômenos de determinada realidade (TRIVIÑOS, 1987); no caso desta pesquisa, propõe-se a descrever o conhecimento contábil e fiscal e as fontes de assessoramento dos produtores rurais pesquisados.

Quanto aos procedimentos técnicos, o estudo configura uma pesquisa de levantamento. Para Moreira e Caleffe (2008), é o tipo de pesquisa descritiva mais comum, e inclui a utilização de questionários, o que justifica tal classificação. Diante disso, discorre-se sobre o tratamento dos dados quanto à sua coleta e análise. A população desta pesquisa é composta por pequenos e médios produtores rurais do município de Santa Maria, RS. A definição deste munícipio ocorreu em virtude de as pesquisadoras residirem na respectiva cidade, facilitando a coleta dos dados.

Segundo a Prefeitura Municipal de Santa Maria (PMSM), em fevereiro de 2020, havia um total de 4.683 produtores rurais registrados no município, caracterizados como pequenos e médios produtores rurais. Destaca-se que, em Santa Maria, não há produtores rurais classificados como grande produtor. Não foi possível estipular destes produtores rurais quantos são ou não cooperados, logo não se estabeleceu uma amostra mínima a ser coletada (HAIR JR. et al., 2009), por isso, não se espera generalizar os resultados auferidos. Os respondentes foram escolhidos por acessibilidade, tendo em vista facilidade na proximidade dos pesquisadores para a coleta dos dados.

A coleta de dados foi realizada individualmente, de modo presencial, em março de 2020, com o auxílio da Secretaria de Desenvolvimento Rural, situada na PMSM. Os pesquisadores mantiveram total precaução quanto à pandemia do COVID-19. O questionário, adaptado de Ambrós et al. (2019), foi aplicado na PMSM, constituído de questões abertas e fechadas e composto por dois blocos de questões. O primeiro bloco 
contemplou questionamentos sobre o perfil do respondente. Para fazer parte da amostra pesquisada, o produtor rural deveria responder se era ou não cooperado de alguma cooperativa rural, sendo esta uma das questões do perfil.

O perfil do respondente levantou informações sobre idade, sexo, estado civil, escolaridade, enquadramento da atividade (pessoa física ou jurídica), tempo na atividade rural e se exerce alguma atividade em paralelo à atividade rural. Ainda foi questionado sobre a propriedade rural, se ela era própria, arrendada, parceria, comodato ou condomínio e as principais atividades rurais desempenhadas pelos pesquisados. Para identificar o conhecimento contábil e fiscal dos cooperados, a adoção do profissional contábil e de outras fontes de assessoramento e a preparação e o apoio contábil para a NFE, utilizou-se o instrumento de Ambrós et al. (2019). O Quadro 1 apresenta as variáveis pesquisadas.

Quadro 1 - Constructos e variáveis pesquisadas

\begin{tabular}{|c|c|}
\hline \multicolumn{2}{|r|}{ Conhecimentos Contábeis (CC) } \\
\hline $\mathrm{CC} 1$ & Tenho conhecimento sobre assuntos contábeis. \\
\hline $\mathrm{CC} 2$ & Procuro me atualizar sobre informações contábeis. \\
\hline CC3 & Tenho conhecimento sobre o controle do meu patrimônio e o resultado da minha atividade. \\
\hline $\mathrm{CC} 4$ & Ter um contador é algo obrigatório para minha atividade. \\
\hline $\mathrm{CC} 5$ & A contabilidade auxilia no controle de entradas e saídas da minha atividade rural. \\
\hline \multicolumn{2}{|r|}{ Conhecimentos Fiscais (CF) } \\
\hline CF6 & Tenho conhecimento sobre como devo obter e arquivar talões de nota fiscal de produtor. \\
\hline CF7 & Tenho conhecimento sobre como preencher a nota fiscal do talão de produtor. \\
\hline CF8 & Tenho conhecimento sobre o Imposto de Renda Pessoa Física para a atividade rural. \\
\hline CF9 & Há incidência de ICMS sobre o valor da produção rural nas notas fiscais. \\
\hline CF10 & Tenho conhecimento sobre a Declaração do Imposto sobre a Propriedade Territorial Rural. \\
\hline \multicolumn{2}{|r|}{ Utilização dos Serviços do Profissional Contábil (PC) } \\
\hline PC11 & Um profissional contábil faz a minha declaração de ITR. \\
\hline PC12 & Um profissional contábil faz a minha declaração de Imposto de Renda. \\
\hline PC13 & Procuro um profissional contábil quando tenho dúvidas ou preciso decidir sobre empresa. \\
\hline PC14 & Tenho acompanhamento de um profissional contábil. \\
\hline PC15 & Um profissional contábil controla ou me auxilia em investimentos e financiamentos. \\
\hline PC16 & Um profissional que é da área contábil me assessora nas questões fiscais e tributárias. \\
\hline \multicolumn{2}{|r|}{ Preparação para NFE (PNF) } \\
\hline PNF17 & Tenho conhecimento de quando a NFE passará a ser obrigatória para minhas operações. \\
\hline PNF18 & Tenho computador e internet disponíveis. \\
\hline PNF19 & Estou com tudo pronto para atender à exigência da NFE. \\
\hline PNF20 & Sei emitir uma NFE para a minha atividade rural. \\
\hline PNF21 & Já estou utilizando a NFE. \\
\hline \multicolumn{2}{|r|}{ Apoio Contábil para NFE (ANF) } \\
\hline ANF22 & Procurei ou vou procurar um profissional contábil para me auxiliar com a NFE. \\
\hline ANF23 & O profissional contábil que trabalha para mim resolverá ou está resolvendo as questões da NFE. \\
\hline ANF24 & O contador do órgão que participo (Sindicato, Cooperativa, etc.) me ajuda ou ajudará com a NFE. \\
\hline ANF25 & O profissional contábil que auxilia outro produtor rural me ajuda ou ajudará com a NFE. \\
\hline ANF26 & Nã̃o contarei com o apoio contábil (profissional contábil) para emissão da NFE. \\
\hline \multicolumn{2}{|r|}{ Outras Fontes de Apoio (OFA) } \\
\hline OFA27 & $\begin{array}{l}\text { Para assuntos fiscais, contábeis ou financeiros, busco a cooperativa de que participo ou da qual já } \\
\text { participei. }\end{array}$ \\
\hline OFA28 & $\begin{array}{l}\text { Para assuntos fiscais, contábeis ou financeiros, busco o sindicato de que participo ou do qual já } \\
\text { participei. }\end{array}$ \\
\hline OFA29 & Para assuntos fiscais, contábeis ou financeiros, busco um órgão do governo para me auxiliar. \\
\hline OFA30 & 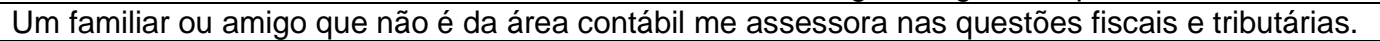 \\
\hline
\end{tabular}

Fonte: Adaptado de Ambrós et al. (2019).

As questões do Quadro 1 foram respondidas pelos produtores rurais conforme uma escala Likert, correspondendo a seguinte gradação: 0 = Não se aplica, $1=$ Discordo Totalmente, $2=$ Discordo Parcialmente, $3=$ Indiferente (Não Concordo nem Discordo), 4 = Concordo Parcialmente e 5 = Concordo Totalmente, de acordo com a percepção do respondente diante de cada uma das 30 assertivas que compõem o instrumento.

A coleta de dados ocorreu ao longo do mês de março de 2020, de forma que os questionários foram aplicados presencialmente na Secretaria de Desenvolvimento Rural situada na PMSM, momento em que cada produtor rural foi convidado a participar da pesquisa. Esclarece-se que para a coleta dos dados as pesquisadoras mantiveram total precaução quanto ao distanciamento social e o uso de máscara, tendo em vista as circunstâncias impostas pela pandemia do COVID-19. As perguntas foram realizadas pelas pesquisadoras de modo individual para cada produtor rural, no intuito de esclarecer dúvidas e obter respostas fidedignas à realidade do pesquisado. $\mathrm{O}$ instrumento foi coletado fisicamente, sendo posteriormente tabulado 
em planilha eletrônica.

A partir da coleta obteve-se um total de 110 questionários respondidos. Esses questionários foram tabulados no programa Microsoft Office Excel®. Após conferência, foram importados para o software Statistical Package for the Social Sciences $\AA$ (SPSS), a partir do qual foram realizadas as análises estatísticas. Inicialmente realizou-se a estatística descritiva, com mínimos, máximos, média, desvio padrão e mediana. Para o tratamento e análise dos resultados, considerou-se uma padronização da escala para escala de razão de 0 a $100 \%$, os quais são convencionados nas três categorias (Baixa, Moderada e Alta, por exemplo, utilização dos serviços do profissional contábil). Logo, a padronização ocorreu da seguinte forma: Alta, para média de 66,67\% a 100\%; Moderada, para média entre 33,34\% a 66,66\%; e, Baixa, para média de 0 a 33,33\% (LOPES, 2016).

Em seguida, para estimar a confiabilidade foi medida a consistência interna por meio do coeficiente Alfa de Cronbach (SAMPIERI; COLLADO; LUCIO, 2013). Posteriormente, foi realizada análise comparativa entre cooperados e não cooperados, para isso foi utilizado o Teste "U" de Mann-Whitney para a comparação de amostras independentes, indicado para amostras com distribuição não normal, teste não-paramétrico. A normalidade dos dados foi apurada pelos testes de Kolmogorov-Smirnov e Shapiro-Wilk. A partir disso alcançaram-se os objetivos estabelecidos e respondeu-se o problema de pesquisa levantado. A seguir apresenta-se a análise e discussão dos resultados.

\section{ANÁLISE E DISCUSSÃO DOS RESULTADOS}

Neste capítulo constam os resultados que foram encontrados a partir da coleta e análise dos dados. Inicialmente apresenta-se a caracterização do perfil dos pesquisados, sendo a amostra composta por produtores rurais de Santa Maria/RS. Em seguida, detalham-se os resultados envoltos aos constructos pesquisados.

\subsection{Perfil dos Produtores Rurais}

A amostra foi composta por 110 respondentes, pequenos e médios produtores rurais do município de Santa Maria - RS, sendo 55 cooperados de diferentes cooperativas rurais da região e 55 não cooperados. Destaca-se que todos os respondentes possuíam o talão de produtor rural devidamente emitido pela Prefeitura Municipal de Santa Maria. A Tabela 1 apresenta a faixa etária dos respondentes segregados em cooperados e não cooperados.

Tabela 1 - Faixa etária dos produtores rurais

\begin{tabular}{c|c|c|c|c|c|c}
\hline \multirow{2}{*}{ Faixas Etárias } & \multicolumn{2}{|c|}{ Geral } & \multicolumn{2}{c|}{ Cooperados } & \multicolumn{2}{c}{ Não Cooperados } \\
\cline { 2 - 6 } & Qnt. & $\%$ & Qnt. & $\%$ & Qnt. & $\%$ \\
\hline Menor de 18 anos & 0 & $0 \%$ & 0 & $0 \%$ & 0 & $0 \%$ \\
\hline 18 até 30 & 4 & $3,6 \%$ & 2 & $3,6 \%$ & 2 & $3,6 \%$ \\
\hline 31 até 40 & 9 & $8,2 \%$ & 7 & $12,7 \%$ & 2 & $3,6 \%$ \\
\hline 41 até 50 & 25 & $22,7 \%$ & 9 & $16,4 \%$ & 16 & $29,1 \%$ \\
\hline 51 até 60 & 35 & $31,8 \%$ & 22 & $40 \%$ & 13 & $23,6 \%$ \\
\hline Acima de 60 anos & 37 & $33,6 \%$ & 15 & $27,3 \%$ & 22 & $40 \%$ \\
\hline TOTAL & $\mathbf{1 1 0}$ & $\mathbf{1 0 0} \%$ & $\mathbf{5 5}$ & $\mathbf{1 0 0} \%$ & $\mathbf{5 5}$ & $\mathbf{1 0 0} \%$ \\
\hline
\end{tabular}

Fonte: Autoras.

A partir da Tabela 1 percebe-se que a amostra pesquisada, no geral, tem mais de 60 anos de idade $(33,6 \%)$, seguida pelos respondentes entre 51 e 60 anos $(31,8 \%)$. Comparando cooperados e não cooperados, observa-se que para os respondentes cooperados prevaleceu a idade entre 51 e 60 anos (40\%), enquanto para os não cooperados sobressaiu-se a faixa etária acima de 60 anos. A elevada faixa etária dos produtores rurais pode ser consequência do crescimento do êxodo rural, que vem resultando em uma tendência ao envelhecimento no campo (BOESSIO; DOULA, 2016). Os autores concluíram na sua pesquisa que, na percepção dos jovens, a cooperativa é vista como instituição incentivadora da permanência dos mesmos no campo, seja em função do incentivo familiar, como pelo fato de a cooperativa oferecer condições para melhorias na produção agropecuária, o que pode explicar essa tendência de concentração de produtores cooperados em faixas etárias inferiores aos 60 anos.

No que se refere ao sexo, a maioria da amostra pesquisada é do sexo masculino $(68 \%, 75$ respondentes). Ao comparar os sexos entre os grupos de cooperados e não cooperados, aufere-se que, no grupo de produtores cooperados, mais de $80 \%$ correspondem ao sexo masculino ( $82 \%, 45$ respondentes), enquanto, para o grupo de não cooperados, houve maior equilíbrio, sendo $54,5 \%$ de homens (30 produtores) e $45,5 \%$ de mulheres (25 produtoras). Estudos recentes apontam para um aumento gradativo da força de trabalho feminina na cadeia produtiva do agronegócio, mas destaca-se que, apesar deste crescimento, ainda, 
são verificadas diversas desigualdades em relação à força de trabalho no meio rural (BUTRI, 2019).

A participação das mulheres como cooperadas, no agronegócio, é motivada pela oportunidade de atuação, propiciando a comercialização de produtos resultantes de atividades, como a produção de alimentos, o cultivo de hortas, o cuidado de animais de pequeno porte, entre outras, geralmente destinadas à subsistência da família (SALVARO; ESTEVAM; FELIPE, 2014). Quanto ao estado civil, no geral, a amostra pesquisada possui o status de casada ( $70 \%, 77$ respondentes), seguido dos solteiros (19\%, 21 respondentes) e dos viúvos e divorciados, respectivamente, $6,4 \%$ e $4,5 \%$ cada. Por grupo, cooperado e não cooperado, os resultados obtidos para estado civil se mantiveram semelhantes à amostra geral.

$\mathrm{Na}$ Tabela 2, é evidenciada a escolaridade dos produtores rurais pesquisados.

Tabela 2 - Escolaridade dos produtores rurais

\begin{tabular}{l|c|c|c|c|c|c}
\hline \multicolumn{1}{c|}{ Escolaridade } & \multicolumn{2}{c|}{ Geral } & \multicolumn{2}{c|}{ Cooperados } & \multicolumn{2}{c}{ Não Cooperados } \\
\cline { 2 - 7 } & Qnt. & $\%$ & Qnt. & $\%$ & Qnt. & $\%$ \\
\hline Não estudou & 3 & $2,7 \%$ & 1 & $1,8 \%$ & 2 & $3,6 \%$ \\
\hline Ensino fundamental incompleto & 44 & $40,0 \%$ & 17 & $31 \%$ & 27 & $49,1 \%$ \\
\hline Ensino fundamental completo & 18 & $16,4 \%$ & 9 & $16,4 \%$ & 9 & $16,4 \%$ \\
\hline Ensino médio incompleto & 2 & $1,8 \%$ & 1 & $1,8 \%$ & 1 & $1,8 \%$ \\
\hline Ensino médio completo & 27 & $24,5 \%$ & 18 & $32,7 \%$ & 9 & $16,4 \%$ \\
\hline Curso técnico em andamento ou concluído & 1 & $0,9 \%$ & 1 & $1,8 \%$ & 0 & $0,0 \%$ \\
\hline Curso superior em andamento ou concluído & 15 & $13,6 \%$ & 8 & $14,5 \%$ & 7 & $12,7 \%$ \\
\hline \multicolumn{1}{c|}{ TOTAL } & $\mathbf{1 1 0}$ & $\mathbf{1 0 0} \%$ & $\mathbf{5 5}$ & $\mathbf{1 0 0} \%$ & $\mathbf{5 5}$ & $\mathbf{1 0 0 \%}$ \\
\hline
\end{tabular}

Fonte: Autoras.

Conforme demonstra a Tabela 2, no geral, a amostra pesquisada apresenta ensino fundamental incompleto (40\%). Ao aprofundar a análise descritiva entre os cooperados e não cooperados, observa-se que os produtores rurais não cooperados apresentam menor grau de escolaridade frente aos cooperados. Estudos similares, também, evidenciam que, no geral, os produtores rurais possuem baixa escolaridade ou, até mesmo, escolaridade incompleta e são influenciados por aspectos culturais e familiares no modo de gerenciamento das propriedades rurais (SANTOS E. et al., 2019), sendo esta relação entre escolaridade e fatores culturais uma possível explicação para o fato de que, quanto maior a escolaridade, maior é a tendência do agricultor estar vinculado a uma cooperativa, por entender que, quanto mais esclarecido o produtor rural, mais entendimento ele terá sobre o processo do cooperativismo e suas vantagens para suas atividades no agronegócio.

Todos os produtores rurais responderam estar enquadrados como pessoa física. Para Santos F. et al. (2019), esse enquadramento traz benefícios para os produtores rurais, como facilidades para gerar a nota fiscal, menor incidência de impostos e vantagens no consumo de água, luz e na compra de veículos. Além disso, a maioria dos produtores pesquisados exerce a atividade de produtor rural há mais de 31 anos $(54,5 \%)$, conforme verifica-se na Tabela 3.

Tabela 3 - Tempo de atuação na atividade rural

\begin{tabular}{c|c|c|c|c|c|c}
\hline \multirow{2}{*}{ Tempo de Atuação } & \multicolumn{2}{|c|}{ Geral } & \multicolumn{2}{c}{ Cooperados } & \multicolumn{2}{c}{ Não Cooperados } \\
\cline { 2 - 6 } & Qnt. & $\%$ & Qnt. & $\%$ & Qnt. & $\%$ \\
\hline De 1 a 5 anos & 7 & $6,4 \%$ & 0 & $0 \%$ & 7 & $12,7 \%$ \\
\hline De 6 a 10 anos & 5 & $4,5 \%$ & 3 & $5,4 \%$ & 2 & $3,6 \%$ \\
\hline De 11 a 20 anos & 17 & $15,5 \%$ & 9 & $16,4 \%$ & 8 & $14,5 \%$ \\
\hline De 21 a 30 anos & 21 & $19,1 \%$ & 10 & $18,2 \%$ & 11 & $20,0 \%$ \\
\hline Mais de 31 anos & 60 & $54,5 \%$ & 33 & $60 \%$ & 27 & $49,1 \%$ \\
\hline TOTAL & $\mathbf{1 1 0}$ & $\mathbf{1 0 0} \%$ & $\mathbf{5 5}$ & $\mathbf{1 0 0} \%$ & $\mathbf{5 5}$ & $\mathbf{1 0 0} \%$ \\
\hline
\end{tabular}

De modo geral, a partir da Tabela 3, percebe-se que $73,6 \%$ da amostra pesquisada têm mais de 20 anos de atuação na atividade rural, o que, também, pode estar relacionado à elevada idade dos produtores rurais. Nenhum dos produtores pesquisados tem menos de um ano de tempo de atuação. Comparando cooperados e não cooperados, percebe-se que os resultados são semelhantes aos encontrados na amostra geral.

Quanto à propriedade rural, $83(75,5 \%)$ produtores rurais responderam ter propriedade própria; 36 $(32,7 \%)$ arrendada; e $7(6,4 \%)$, responderam ter propriedade rural na forma de comodato. Destaca-se que, na atividade rural, é comum que o uso da propriedade rural ocorra em mais de um formato, por exemplo, sendo parte própria e parte arrendada. Esses resultados reforçam as distintas modalidades de uso da terra na atividade rural, conforme elencam Crepaldi (2019), Marion (2017) e Rodrigues et al. (2016). Na comparação entre cooperados e não cooperados, não se verificaram diferenças significativas quanto à forma de uso da propriedade diante dos resultados levantados para a amostra geral. 
No que se refere a exercer outra atividade em paralelo à atividade rural, verificou-se que, aproximadamente, $82 \%$ dos produtores rurais exercem somente a atividade rural, e os outros $18 \%$ exercem outra atividade além da rural. Ao comparar cooperados e não cooperados, verificou-se o mesmo resultado para ambos. Esses dados evidenciam que a atividade rural é suficiente para a geração de renda para os pequenos e médios produtores pesquisados. Sakamoto, Nascimento e Maia (2016) destacam que a escolaridade do produtor rural possui forte relação com a renda da propriedade, sendo a escolaridade e a elevada faixa etária dos pesquisados uma possível determinante para o fato de que os mesmos exercem apenas a atividade rural.

Dentre as atividades rurais desempenhadas, identificou-se, entre os pesquisados, que 31 desempenham apenas uma atividade rural, sendo a pecuária (14 respondentes) e agricultura, especificamente a soja (14 respondentes), as principais monoculturas, seguidas da cultura do arroz (3 respondentes). Os demais produtores responderam desempenharem mais de uma atividade rural, o que corresponde a, aproximadamente, $72 \%$ da amostra pesquisada e evidencia a prevalência de multiculturas, isso pode ser justificado por Schmidt et al. (2019). Para os autores. fatores como a perecibilidade, sazonalidade de oferta, susceptibilidade climática, variabilidade de preços, dentre outros fatores, que interferem na execução da atividade rural e incentivam a diversificação das culturas.

Sobre as atividades rurais desempenhadas, observou-se que a maioria, $54,5 \%$ (60) dos produtores rurais, atuam na pecuária, sendo a principal atividade exercida pelos produtores rurais pesquisados, seja como monoatividade ou em consonância a outras atividades. Sabe-se que a principal característica no desenvolvimento dessa atividade é a heterogeneidade nos sistemas de produção e nos mecanismos de gestão e de comercialização do gado (CARVALHO; ZEN, 2017). Os autores destacam que, dentro das pequenas e médias propriedades rurais, o setor tem apresentado avanços no emprego de tecnologias, na diversificação de atividades e de novas formas de comercialização, com a indústria de insumos e com os frigoríficos, podendo ser esta diversidade e maior facilidade na comercialização um diferencial deste ramo de atividade.

Além da pecuária, a cultura da soja foi mencionada por 43 produtores. Estudos apontam a cultura da soja como sendo de grande importância para a economia do Brasil, sendo a principal do agronegócio brasileiro, destacando-se, ainda, como uma das atividades econômicas que mais cresceu no País, sendo que o "complexo soja" lidera a pauta exportadora nacional em valor (SANTOS, 2020), sendo o cenário de crescimento constante da soja um motivador para que se amplie a cultura da mesma.

As culturas de milho e arroz também constam entre as principais atividades cultivadas pelos produtores rurais pesquisados, entre 20 e 22\%, respectivamente. Salienta-se que, de modo geral, houve redução junto à atuação dessas culturas, principalmente, substituídas pela soja e pela pecuária. Conforme a Companhia Nacional de Abastecimento - CONAB (2020), ambas culturas apresentaram redução na área e na produção na safra 2019/2020.

A amostra pesquisada é caracterizada por homens (82\%) com mais de 50 anos $(65,4 \%)$, casados (70\%), com ensino fundamental incompleto (40\%), que exercem somente a atividade rural (82\%) há mais de 31 anos $(60 \%)$, sob a forma de pessoa física, em propriedade rural própria $(75,5 \%)$, com principais atividades rurais, a pecuária seguida da soja. Ao comparar o perfil dos produtores rurais que são cooperados e os não cooperados, verificaram-se algumas diferenças quanto à faixa etária, ao sexo e à escolaridade. A seguir, esmiúça-se a análise descritiva.

\subsection{Análise Descritiva}

A análise descritiva contemplou 30 variáveis distribuídas em seis constructos do instrumento adaptado de Ambrós et al. (2019). Essa estatística considerou como pontuações: média, razão, desvio padrão e mediana, obtidas nas 110 respostas. Na Tabela 4, consta a estatística descritiva dos constructos.

Tabela 4 - Estatística descritiva dos constructos

\begin{tabular}{|c|c|c|c|c|c|c|c|c|c|c|c|c|}
\hline \multirow{2}{*}{ Constructo } & \multicolumn{4}{|c|}{ Geral } & \multicolumn{4}{|c|}{ Cooperados } & \multicolumn{4}{|c|}{ Não Cooperados } \\
\hline & Média & Razão & DP & Mediana & Média & Razão & DP & Mediana & Média & Razão & DP & Mediana \\
\hline $\mathrm{CC}$ & 2,89 & Moderada & ,693 & 2,6 & 3,06 & Moderada & ,731 & 2,6 & 2,72 & Moderada & ,639 & 2,6 \\
\hline $\mathrm{CF}$ & 3,38 & Alta & 769 & 3,4 & 3,67 & Alta & 656 & 3,4 & 2,97 & Moderada &, 730 & 3,4 \\
\hline $\mathrm{PC}$ & 2,16 & Moderada & 1,425 & 1,16 & 2,64 & Moderada & 1,464 & 1,7 & 1,68 & Moderada & 1,185 & 1,0 \\
\hline PNF & 2,11 & Moderada &, 911 & 2 & 2,43 & Moderada &, 927 & 2,2 & 1,79 & Moderada & ,779 & 1,8 \\
\hline ANF & 2,50 & Moderada & ,456 & 2,6 & 2,60 & Moderada & ,495 & 2,6 & 2,40 & Moderada & ,393 & 2,4 \\
\hline OFA & 2,73 & Moderada & ,869 & 2,75 & 2,92 & Moderada & ,844 & 3,0 & 2,54 & Moderada &, 639 & 2,2 \\
\hline
\end{tabular}

Fonte: Autoras.

Diante da Tabela 4, cabe destacar o constructo CF (Conhecimentos Fiscais) que, para os produtores rurais cooperados, auferiu razão alta, o que representa que os produtores rurais que são cooperados apresentam maior conhecimento referente a esta temática. Nesse sentido, destaca-se o papel das 
cooperativas no sentido de prestarem assessoramento aos seus cooperados, explicando o fato de que estes tenham obtido maior grau de conhecimento. Os demais constructos, quanto à média, obtiveram razão moderada.

A partir da comparação entre produtores rurais cooperados e não cooperados, evidenciada pela estatística descritiva, constata-se que as médias dos cooperados foi superior aos não cooperados em todos os constructos pesquisados. Complementarmente, para as medianas, verifica-se que os produtores rurais cooperados também auferiram medianas com valores maiores frente aos produtores que não são cooperados, corroborando para a análise das médias e razões.

Ao observar o desvio padrão, que evidencia a uniformidade das respostas obtidas em cada uma das assertivas, destaca-se o constructo de utilização dos serviços do profissional contábil (PC) que apresentou maior desvio padrão, evidenciando uma falta de uniformidade nas respostas apresentadas; em contrapartida, o constructo de apoio contábil para NFE apresentou maior uniformidade nas respostas dadas pelos produtores rurais cooperados, explicada pela não obrigatoriedade da emissão de NFE.

Em seguida, mensurou-se o Alfa de Cronbach que resultou em $\alpha=0,829$. O valor desse coeficiente pode variar de 0 a 1 , sendo que, quanto mais próximo de 1 , melhor a confiabilidade, pois maior será a consistência interna do instrumento (HAIR JR. et al., 2009). Diante disso, considera-se que o resultado obtido para o instrumento aplicado é confiável. Com base nisso, deu-se seguimento às análises. A seguir, apresentase a análise comparativa.

\subsection{Comparação entre produtores rurais cooperados e não cooperados}

Para analisar as comparações entre os produtores rurais cooperados e não cooperados quanto aos conhecimentos contábil e fiscal, preparação e apoio para NFE e fontes de assessoramento, por conseguinte, utilizou-se o teste não paramétrico Mann-Whitney para amostras independentes, tendo em vista a não normalidade apurada pelos testes de Kolmogorov-Smirnov e Shapiro-Wilk (Tabela 5).

Tabela 5 - Testes de normalidade ${ }^{a}$

\begin{tabular}{c|c|c|c|c}
\hline \multirow{2}{*}{ Constructo } & \multicolumn{2}{|c}{ Kolmogorov-Smirnov ${ }^{\mathbf{b}}$} & \multicolumn{2}{c}{ Shapiro-Wilk } \\
\cline { 2 - 4 } & Estatística & Sig. & Estatística & Sig. \\
\hline Conhecimento Contábil &, 243 &, 000 &, 847 &, 000 \\
\hline Conhecimento Fiscal &, 109 &, 003 &, 970 &, 014 \\
\hline Profissional Contábil &, 275 &, 000 &, 759 &, 000 \\
\hline Preparação para a NFE &, 124 &, 000 &, 890 &, 000 \\
\hline Apoio para a NFE &, 239 &, 000 &, 837 &, 000 \\
\hline Outras Fontes de Assessoramento &, 100 &, 009 &, 973 &, 024 \\
\hline \multicolumn{2}{|c}{ a n. 110. }
\end{tabular}

b Correlação de Significância de Lilliefors Fonte: Autoras.

A partir do teste de normalidade (Tabela 5), realizou-se a comparação entre os dois grupos pesquisados. A Tabela 6 demonstra o rankeamento (postos) assumido pelos produtores rurais cooperados $\mathrm{e}$ não cooperados para os seis constructos pesquisados.

Tabela 6 - Rankeamento dos produtores rurais cooperados e não cooperados

\begin{tabular}{c|c|c|c|c}
\hline Constructo & É cooperado & $\mathbf{N}$ & Posto Médio & Soma de Postos \\
\hline \multirow{2}{*}{ Conhecimento Contábil (CC) } & Sim & 55 & 63,48 & 3491,50 \\
\cline { 2 - 4 } & Não & 55 & 47,52 & 2613,50 \\
\hline \multirow{2}{*}{ Conhecimento Fiscal (CF) } & Sim & 55 & 69,70 & 3833,50 \\
\cline { 2 - 4 } & Não & 55 & 41,30 & 2271,50 \\
\hline \multirow{2}{*}{ Profissional Contábil (PC) } & Sim & 55 & 65,16 & 3584,00 \\
\cline { 2 - 4 } & Não & 55 & 45,84 & 2521,00 \\
\hline \multirow{2}{*}{ Preparação para a NFE (PNF) } & Sim & 55 & 67,26 & 3699,50 \\
\cline { 2 - 4 } & Não & 55 & 43,74 & 2405,50 \\
\hline \multirow{2}{*}{ Apoio para a NFE (ANF) } & Sim & 55 & 60,75 & 3341,50 \\
\cline { 2 - 4 } & Não & 55 & 50,25 & 2763,50 \\
\hline \multirow{2}{*}{ Outras fontes de assessoramento (OFA) } & Sim & 55 & 63,18 & 3475,00 \\
\cline { 2 - 4 } & Não & 55 & 47,82 & 2630,00 \\
\hline
\end{tabular}

A partir dos postos assumidos, observa-se que para os seis constructos pesquisados: conhecimento Contábil, Conhecimento Fiscal, utilização dos serviços do Profissional Contábil, Preparação e Apoio para a NFE e uso de Outras Fontes de Assessoramento, os produtores rurais cooperados atingiram pontuações 
superiores aos produtores que não são cooperados. Diante disso, desenvolveu-se a Tabela 7 que apresenta os resultados para Teste de Mann-Whitney.

Tabela 7 - Comparaçãoab entre produtores cooperados e não cooperados

\begin{tabular}{l|c|c|c|c|c|c} 
& CC & CF & PC & PNF & ANF & OFA \\
\cline { 2 - 7 } & 1073,500 & 731,500 & 981,000 & 865,500 & 1223,500 & 1090,000 \\
\hline U de Mann-Whitney & 2613,500 & 2271,500 & 2521,000 & 2405,500 & 2763,500 & 2630,000 \\
\hline Z & $-2,687$ & $-4,689$ & $-3,373$ & $-3,901$ & $-1,788$ & $-2,544$ \\
\hline Significância Assint. (Bilateral) &, 007 &, 000 &, 001 &, 000 &, 074 &, 011 \\
\hline
\end{tabular}

Diante da Tabela 7, observa-se que a significância obtida na comparação entre cooperados e não cooperados, para quase todos os constructos, obteve valores inferiores a 0,05 , com exceção do constructo de ANF - Apoio para a NFE, que não se revelou significativo. O teste Mann-Whitney evidenciou que ser cooperado tem efeito sobre os constructos de conhecimento contábil $(U=1073,5 ; p<0,01)$ e fiscal $(U=$ $731,5 ; p<0,01)$, utilização dos serviços do profissional da contabilidade $(U=981,0 ; p<0,01)$, preparação para a NFE $(U=865,5 ; p<0,01)$ e utilização de outras fontes de assessoramento $(U=1090,0 ; p<0,05)$, mas não para o apoio para a NFE $(U=1223,5 ; p>0,05)$.

No geral, observa-se que ser associado de alguma cooperativa rural proporciona maior nível de conhecimento aos produtores rurais. Nesse sentido, o estudo desenvolvido por Kremer et al. (2018) reforça os achados encontrados nesta pesquisa, uma vez que os autores identificaram que as cooperativas podem incentivar a aprendizagem interdisciplinar dos produtores rurais, uma vez que as mesmas proporcionam vantagens aos cooperados, tais como o acesso a informações técnicas e a conteúdo de eventos, a palestras e a encontros (KREMER et al., 2018).

Ainda, pode-se relacionar os resultados encontrados ao quinto princípio do cooperativismo, da educação, da formação e da informação, uma vez que a cooperativa é capaz de proporcionar acesso a informações das mais diversas áreas do conhecimento (KREMER et al., 2018). Isso reforça o diferente grau de conhecimento evidenciado entre os produtores rurais cooperados e não cooperados, uma vez que as cooperativas investem no desenvolvimento do cooperado, embasando-se no desenvolvimento e na prática do princípio do cooperativismo, que deve ser observado pelas cooperativas, independente do ramo de atuação.

Assim sendo, verifica-se o importante papel da cooperativa para garantir o acesso do produtor rural ao conhecimento contábil, à utilização dos serviços do profissional contábil, à preparação para NFE e outras fontes de assessoramento, aprofundando a análise a partir das diferenças entre os postos (Tabela 6). Observa-se que, para os constructos pesquisados, os valores foram maiores para os produtores rurais que são associados de alguma cooperativa rural, respondendo, assim, a problemática pesquisada, evidenciando a relevância das cooperativas rurais enquanto assistência e proximidade informacional para o homem do campo.

\section{CONCLUSÃO}

O presente estudo teve como objetivo analisar produtores rurais cooperados e não cooperados quanto ao conhecimento contábil e fiscal, preparação e apoio para a Nota Fiscal Eletrônica - NFE, e a utilização dos serviços do profissional contábil ou de outras fontes de assessoramento. Para alcançar esse objetivo, inicialmente, apresentou-se o perfil dos produtores rurais pesquisados. No geral, a amostra de 110 produtores rurais é caracterizada por homens (82\%), com mais de 50 anos $(65,4 \%)$, casados $(70 \%)$, com ensino fundamental incompleto (40\%), que exercem somente a atividade rural $(82 \%)$, há mais de 31 anos $(60 \%)$, sob a forma de pessoa física, em propriedade rural própria (75,5\%), como principais atividades rurais a pecuária, seguida da agricultura, especificamente, a soja. Ao comparar o perfil dos produtores rurais que são cooperados e os que não são cooperados, verificaram-se algumas diferenças quanto à faixa etária, ao sexo e à escolaridade.

Em seguida, verificaram-se os conhecimentos contábil e fiscal, a preparação e o apoio para a NFE dos produtores rurais pesquisados, e identificou-se a utilização dos serviços do profissional contábil e de outras fontes de assessoramento pelos produtores rurais. Constatou-se que os produtores pesquisados têm alto conhecimento fiscal; os demais constructos constaram em razão moderada. Além disso, a preparação para NFE obteve a menor pontuação, evidenciando que os produtores não se sentem preparados para tal exigência. Ainda, observou-se que os produtores pesquisados preferem outras fontes de assessoramento frente ao profissional contábil.

Por fim, compararam-se os constructos pesquisados entre os produtores rurais cooperados e os não 
cooperados. Os resultados apontaram que os produtores rurais que são cooperados de cooperativas agropecuárias apresentam maior conhecimento contábil e fiscal, utilizam mais o profissional da área contábil e outras fontes de assessoramento, e estão mais preparados para a NFE frente aos produtores rurais que não são cooperados.

Contribuições acadêmicas e práticas são verificadas nesta pesquisa. Academicamente, contribui para novas pesquisas relacionadas à relevância da cooperativa para o meio rural e de fontes de assessoramento contábil, evidenciando lacunas e oportunidades de atuação. De modo prático, esta pesquisa incentiva e demonstra a relevância da atividade rural como um nicho de mercado favorável para o cooperativismo e para a atuação do profissional contábil. Por meio dessas assistências, o produtor rural pode gerir sua propriedade, acompanhando a evolução e o controle patrimonial e os resultados da atividade.

Esta pesquisa limitou-se a um corte transversal, e a amostra, não representativa, considerou pequenos e médios produtores rurais de Santa Maria, RS. Além disso, limitou-se a uma abordagem quantitativa, com a aplicação de questionário para coleta de dados e análise dos dados com base em estatística. Para os resultados auferidos, não se espera generalização para a população de produtores rurais santa-marienses. Para futuras pesquisas, sugere-se a realização de um estudo longitudinal com produtores rurais cooperados e não cooperados, bem como a replicação desta pesquisa em outros municípios e com grandes produtores rurais. No intuito de aprofundar os achados aqui encontrados, a abordagem qualitativa é indicada, bem como outros instrumentos e métodos de análises podem complementar os resultados ora levantados.

\section{REFERÊNCIAS}

ALMEIDA, K. Z. de. Contabilidade rural: ferramentas estratégicas de apoio a gestão do agronegócio. Trabalho de Conclusão de Curso em Ciências Contábeis da Universidade do Extremo Sul Catarinense, UNESC. 2013.

AMBRÓS, V. A. B.; MARQUEZAN, L. H. F.; ANVERSA, T. S.; RIGON, L. Demanda não obrigatória pelo profissional contábil: uma análise no ambiente dos produtores rurais. Contabilometria - Brazilian Journal of Quantitative Methods Applied to Accounting, Monte Carmelo, v. 6, n. 1, p. 104-121, jan-jun./2019.

BAGENETA, J. M.; RODRÍGUEZ, L. ¿Dinero Para Qué? Cooperativas Agropecuarias Y Reparto de Excedentes en Tiempos de Agronegocio. Revista Americana de Empreendedorismo e Inovação, v. 2, n. 1, 2020.

BATALHA, M. O.; QUEIROZ, T. R. Tomada de decisões em propriedades agrícolas familiares: O uso dos sistemas de custeio e indicadores de desempenho. JCEA; Universidade Federal de Mato Grosso do Sul, 2003.

BIALOSKORSKI NETO, S.; PINTO, A. K. Evolução do Agronegócio e do Cooperativismo Agropecuário: uma análise comparativa de desempenho e impacto econômico. Anais do Encontro Brasileiro de Pesquisadores em Cooperativismo, 2, 2012. Porto Alegre, 2012.

BOEHLJE, M.; ROUCAN-KANE, M.; BRÖRING, S. Future agribusiness challenges: strategic uncertainty, innovation and structural change. International Food and Agribusiness Management Review, v. 14, n. 5, p. 53-82, 2011.

BOESSIO, A. T.; DOULA, S. M. Jóvenes rurales e influencias institucionales para la permanencia en el campo: un estudio de caso en una cooperativa agropecuaria del Triângulo Mineiro. Interações (Campo Grande), v. 17, n. 3, p. 3 70-383, 2016.

BRASIL. Constituição da República Federativa do Brasil de 1988. Disponível em: <http://www.planalto.gov.br/ccivil 03/constituicao/constituicaocompilado.html>. Acesso em 21 nov. 2020.

BRASIL. Decreto n. 1.637. Crea syndicatos profissionaes e sociedades cooperativas. 1907. Disponível em: $<$ https://www2.camara.leg.br/legin/fed/decret/1900-1909/decreto-1637-5-janeiro-1907-582195-publicacaooriginal104950-pl.html>. Acesso em 23 set. 2020.

BRASIL. Decreto-Lei n. 59. Define a política nacional de cooperativismo, cria o Conselho Nacional do Cooperativismo e dá outras Providências. 1966. Disponível em: <http://www.planalto.gov.br/ccivil 03/Decreto-Lei/1965-1988/Del0059.htm>. Acesso em 23 nov. 2020.

BRASIL. Lei n. 5.764. Define a Política Nacional de Cooperativismo, institui o regime jurídico das sociedades cooperativas, e dá outras providências. 1971. Disponível em: <http://www.planalto.gov.br/ccivil 03/LEIS/L5764.htm>. Acesso em 13 dez. 2020.

BRASIL. Lei n. 10.406. Institui o Código Civil. 2002. Disponível em: $<$ http://www.planalto.gov.br/ccivil 03/leis/2002/110406compilada.htm>. Acesso em 23 nov. 2020.

BUTURI, D. K. Participação das mulheres no mercado de trabalho do agronegócio paranaense. 2019. Trabalho de Conclusão de Curso em Ciências Econômicas, Universidade Federal da Integração Latino Americana, 2019.

CARVALHO, T. B. de.; ZEN, S. de. A cadeia de Pecuária de Corte no Brasil: evolução e tendências. Revista iPecege, v. 3, n. 1, p. 85-99, 2017.

COMPANHIA NACIONAL DE ABASTECIMENTO (CONAB). Produção de grãos pode alcançar novo recorde com 248 milhões de toneladas. Notícia. Disponível em: <https://www.conab.gov.br/ultimas-noticias/3210-producao-de-graospode-alcancar-novo-recorde-com-248-milhoes-de-toneladas >. Acesso em 20 nov. 2020. 
COSTA, L. de S. O cooperativismo: uma breve reflexão teórica. Ciências Sociais em Perspectiva, v. 6, n. 11, p. 55-64, 2o sem., 2007.

CREPALDI, A. S. Contabilidade rural: uma abordagem decisorial. 9. ed. SP: Atlas, 2019.

ENGEL, V.; ALMEIDA, G. G. F. de; DEPONTI, C. M. Agricultura familiar no contexto das cooperativas rurais: o caso da Ecocitrus. Cadernos de Ciência \& Tecnologia, Brasília, p. 59-81, abr. 2017.

FREITAG, C.; KLESENER, H. M.; PLEIN, C. Contribuições do Cooperativismo Solidário para Agricultura Familiar e o Desenvolvimento Rural Sustentável. Edição Especial - Cooperativismo e Desenvolvimento Local. Orbis Latina. v. 9 n. 1, 2019.

FUZINATTO, N. M.; et al. Os impactos do cooperativismo de produção no desenvolvimento de pequenos municípios. Gestão e Sociedade, v. 13, n. 35, p. 2901-2929, 22 abr. 2019.

GIANEZINI, M.; et al. O cooperativismo e seu papel no processo de desenvolvimento local: a experiência das cooperativas agrícolas no médio norte de Mato Grosso. Anais do Congresso da Sociedade Brasileira de Economia, Administração e Sociologia Rural - SOBER, ed. 47, Porto Alegre. 2009.

HAIR JR., J. F.; et al. Análise multivariada de dados. 6. ed. Porto Alegre: Bookman, 2009.

ICA - International Co-operative Alliance. What is a co-operative? 2020. Disponível em: $<$ http://www.ica.coop/coop/index>. Acesso em: 23 set. 2020.

JACQUES, E. R.; GONÇALVES, F. de O. Cooperativas de Crédito no Brasil: evolução e impacto sobre a renda dos municípios brasileiros. Economia e Sociedade, v. 25, n. 2, p. 489-509, 2016.

KAMUTALI, A. A. C.; HENRIQUES, P. D.; LUCAS, M. R. Cooperativismo e acesso aos serviços agrícolas na província do Huambo: O caso de cooperativas apoiadas pela ADRA. Revista de Ciências Agrárias, n. 43, p. 61-73. 2020.

KREMER, A. M.; SILVA, I. F. da; AKAHOSHI, W. B.; BINOTTO, E. A formação do conhecimento interdisciplinar do produtor rural: uma abordagem empírica sob o papel de uma cooperativa. Revista da Universidade Vale do Rio Verde, Rio Verde, v. 16, n. 1, p. 1-11, 2018.

KRUGER, S. D.; CECCHIN, R.; MORES, G. de V. A importância da contabilidade para a gestão e continuidade das propriedades rurais. Revista custos e agronegócio on-line, Recife, v. 16, n. 1, p. 276-295, jan./mar., 2020.

LOPES, L. F. D. Métodos quantitativos. Ed. 1. Santa Maria: Universidade Federal de Santa Maria, 2016.

MACIEL, A. P. B.; et al. Governança em Cooperativas: Aplicação em uma Cooperativa Agropecuária. Rev. adm. contemp., v. 22, n. 4, 2018.

MAFFIOLETTI, E. U. As sociedades cooperativas e o regime jurídico concursal: a recuperação de empresas e falências, insolvência civil e liquidação extrajudicial e a empresa cooperativa. Editora: Almedina, 2015.

MARION, J. C. Contabilidade rural: contabilidade agrícola, contabilidade da pecuária, imposto de renda - pessoa jurídica. 14. ed. São Paulo: Atlas, 2017.

MEINEN, E.; PORT, M. Cooperativismo Financeiro, percurso histórico, perspectivas e desafios. Editora Confebras, 2014.

MIRANDA, J. E. Filosofia cooperativa. Curitiba: Juruá, 2017.

MOREIRA, H.; CALEFFE, L. G. Metodologia da pesquisa para o professor pesquisador. 2. ed. Rio de Janeiro: Lamparino, 2008.

OCB, Sistema. Anuário do Cooperativismo Brasileiro. $2019 . \quad$ Disponível em: http://www.paranacooperativo.coop.br/ppc/images/Comunicacao/2019/noticias/07/04/publicacao/publicacao clique aqui 0407 2019.pdf. Acesso em 23 set. 2020.

PEREIRA, F. G. B. Contabilidade de sociedades cooperativas: uma análise da importância da contabilidade para a ascensão do cooperativismo de crédito em Rondonópolis - MT. 57 f. Trabalho de Conclusão de Curso (Graduação em Ciências Contábeis) - Universidade Federal de Mato Grosso, Instituto de Ciências Humanas e Sociais, Rondonópolis, 2020.

PICCININ, Y.; ROSSATO, M. V. Custo da produção agrícola: uma análise do cultivo da soja em uma propriedade rural de Júlio de Castilhos/RS, safra 2016/2017. ABCustos, São Leopoldo: Associação Brasileira de Custos, v. 13, n. 3, p. 90-119, set./dez. 2018.

PIES, M. P.; BAGGIO, D. K.; ROMEIRO, M. C. Participação dos Associados: um pilar estratégico de governança do cooperativismo. RAIMED, v. 6, n. 2, p. 221-236, 2016.

PINHO, D. B. O que é cooperativismo. São Paulo Editora S.A. São Paulo - SP, 1966.

POLONIO. W. A. Manual das sociedades cooperativas. 4. ed. São Paulo: Atlas, 2004.

PRODANOV, C. C.; FREITAS, E. C. Metodologia do trabalho científico: métodos e técnicas da pesquisa e do trabalho acadêmico. 2. ed. ver. e ampl. Rio Grande do Sul: FEEVALE. 2013.

REYNOLDS, A. Defining the value of the cooperative business model: an introduction. 2013. Disponível em: $<$ http://www.uwcc.wisc.edu/pdf/Reynolds Whi tePaper values.pdf>. Acesso em: 22 de set. de 2020.

RODRIGUES, A. O. et al. Contabilidade rural. 4. ed. São Paulo: IOB SAGE, 2016. 
SAKAMOTO, C. S.; NASCIMENTO, C. A.; MAIA, A. G. As Famílias Pluriativas e Não Agrícolas no Rural Brasileiro: condicionantes e diferenciais de renda. Revista de Economia e Sociologia Rural, 54(3), 561-582. 2016.

SALVARO, G. I. J.; ESTEVAM, D. D. O.; FELIPE, D. F. Mulheres em cooperativas rurais virtuais: reflexões sobre gênero e subjetividade. Psicologia: Ciência e Profissão, v. 34, n. 2, p. 390-405. 2014.

SAMPIERI, R. H.; COLLADO, C. F.; LUCIO, M. del P. B. Metodologia de pesquisa. 5. ed. Porto Alegre: Penso, 2013.

SANTOS, D. M. D. A participação do Rio Grande do Sul na evolução da produção da soja no Brasil e a relação com a renda obtida pelos produtores gaúchos (2000 a 2018). Trabalho de Conclusão de Curso, Curso de Ciências Econômicas da UNIJUÍ, 2020.

SANTOS, E. S. F.; et al. A influência da cultura e escolaridade na aplicabilidade do fluxo de caixa rural. Revista Científica da AJES, v. 8, n. 17, 2019.

SANTOS, F. F.; et al. Enquadramento como "Pessoa Física" traz vantagens tributárias aos pequenos agricultores. PUBVET. v. 13, n. 9, a. 420, p. 1-10, Set., 2019.

SCHMIDT, D.; et al. Os Impactos das Variações de Preço nas Culturas de Soja e Milho. ABCustos, São Leopoldo, v. 14, n. 3, p. 56-86, set./dez. 2019.

SCHNEIDER, J. O. Democracia, participação e autonomia cooperativa. São Leopoldo: Unisinos, 1991.

SCOPINHO, R. A. Sobre cooperação e cooperativas em assentamentos rurais. Psicologia \& Sociedade, v. 19, n. 1, p. 84-94. 2007.

SESCOOP/RS. Princípios do Cooperativismo. Disponível em: http://www.sescooprs.coop.br/cooperativismo/principios/. Acesso em: 28 nov. 2020.

TRIVIÑOS, A. N. S. Introdução à pesquisa em ciências sociais: a pesquisa qualitativa em educação. São Paulo: Atlas, 1987. 